\title{
Compound feed production for livestock
}

\author{
D. J. Shrinivasa ${ }^{1, *}$ and S. M. Mathur ${ }^{2}$ \\ ${ }^{1}$ Department of Farm Engineering, Institute of Agricultural Sciences, Banaras Hindu University, Varanasi 221005 , India \\ ${ }^{2}$ Department of Farm Machinery and Power Engineering, College of Technology and Engineering, Maharana Pratap University of Agriculture and \\ Technology, Udaipur 131001 , India
}

\begin{abstract}
Dairying is an important source of subsidiary income to small/marginal farmers and agricultural labourers. Cattle feeding practices are generally traditional and most of the feed comes from grazing. However, due to shortage of feed, there has been a gradual shift from traditional feed pattern to compound feed (CF). For livestock it is either in the form of mash, feed block or feed pellets. With added advantages, the feed block and feed pellets are more popular than the mash. In India, $\mathrm{CF}$ is produced at the industrial level. The CFmaking machines are classified as feed block-making machines and feed pellet-making machines; these are further classified as manually operated, electrical and IC engine-powered machines. The feed pelleting machines available in the market are expensive and thus unaffordable by livestock farmers. If small-scale animal producers have access to a domestically developed pellet mill technology that is low cost yet dependable, then it reduces the dependency on the high cost of commercial feeds available in the market and makes dairy farming more profitable by taking advantages of different feedstuff available at cheap prices, especially during harvest when high-quality ingredients available at low prices.
\end{abstract}

Keywords: Compound feed production, dairy farming, feed blocks and pellets, livestock.

THE livestock sector in India contributes about $4.11 \%$ to the total GDP at current prices ${ }^{1}$. The country is endowed with the largest livestock population in the world, accounting for about $57.3 \%$ of the buffalo population and $14.7 \%$ of the cattle population ${ }^{2}$. Dairying is an important source of subsidiary income to small/marginal farmers and agricultural labourers in India. According to National Sample Survey Office (NSSO) 66th round survey (July 2009-June 2010), the total number of workers in the farming of animals is 20.5 million, and farmers of marginal, small and semi-medium operational holdings ( $<4$ ha) own about $87.7 \%$ of the milch animals.

Cattle-feeding practices are generally traditional and most of the feed comes from grazing. In traditional feeding practices, in addition to shortage of feed, imbalanced nutrition is one of the major factors responsible for low livestock productivity. However, due to shortage of feed, there has been a gradual shift from the age-old pattern to

*For correspondence. (e-mail: shriniv70@gmail.com) compound feed $(\mathrm{CF})^{3}$, which can supply balanced nutrition (supply of nutrients based on physiological conditions of the animals and keeping in view the objective of raising an animal). This ultimately contributes to improving animal output in terms of milk yield and meat yield as well as to reducing the cost of production per unit of animal product produced ${ }^{4}$. In this respect, the technology for making densified total mixed ration blocks (DTMRBs) or densified total mixed ration pellets (DTMRPs) based on straw, milling by-products (agro-processing waste) and oilseed meals is an innovative approach, which provides an opportunity for feed manufacturers and entrepreneurs to remove regional disparities in feed availability and supply balanced feed to dairy and other livestock farmers on a large scale. In addition, feeding of total mixed rations has also been shown to have several advantages such as decrease in feed loss, higher nutrient availability and higher animal performance over feeding ingredients separately ${ }^{5,6}$, which is conventionally practised in many countries. Figure 1 shows the global livestock feed production distribution. It can be seen from the figure that poultry feed production contributes about $45 \%$ to the total global livestock feed production, followed by pig and ruminants feed.

CF products, particularly branded ones, are fast gaining popularity in India (both in rural and urban areas). It is a well-known fact that the livestock feed market in India is classified into three broad categories (Figure 1): poultry feed, cattle feed and aqua feed ${ }^{7}$. It can be seen from Figure 1 that poultry feed production remains the largest livestock feed. CF is used as a supplement, but not as alternative for cattle. Therefore, $\mathrm{CF}$ for cattle is the second largest livestock feed in India. Also, pellet is the most preferred form of $\mathrm{CF}$ with specified advantages like balanced diet, convenience of use and better yield ${ }^{8}$. John and $\mathrm{Manoj}^{9}$ reported the positive opinion of users on $\mathrm{CF}$, and $84 \%$ preferred the pellet form. Almost all livestock feeders agreed that animals make better gains on pelleted feed than a meal ration. Tests have shown that most animals, if given the choice between the same feed in pellet or mashed form, will prefer the former ${ }^{10}$.

\section{Compound feed production process}

The CF production technology for livestock feeding has industrial applications in all regions of India ${ }^{11}$. 


\section{Selection of material}

According to the National Dairy Development Board, Anand, Gujarat, India, the main ingredients for $\mathrm{CF}$ production of cattle are categorized as follows.

1. Grains: maize, sorghum, wheat, rice, oats, barley, ragi, millets, etc.

2. Crop residues: paddy, wheat, millet straw, maize, sorghum stover, etc.

3. Brans: de-oiled rice bran, rice polish, wheat bran, rice bran, etc.

4. Protein meal/cakes: rapeseed meal/cake, soybean meal, cottonseed meal/cake (decorticated and undecorticated), groundnut meal/cake, coconut meal/cake, palm kernel meal/cake, sesame cake, linseed cake, maize germ oil cake, maize gluten meal, sunflower meal, safflower (kardi) meal, guar meal, etc.

5. Chunnies: guar, tur, urd, moong gram and those of other locally available pulses.

6. Agro industrial by-products: molasses, babul chunni, tamarind seed powder, mango kernel extraction, Prosopis juliflora pods, tapioca waste, etc.

7. Minerals and vitamins: mineral mixture, calcite powder, common salt, dicalcium phosphate, and vitamins A, D3 and E.

The ingredients for CF formulation depend especially on the farmer's objectives, animal species and their physiological state for which these supplements are given ${ }^{12}$. Suitable ingredients from the above-mentioned groups will be selected for $\mathrm{CF}$ production. The formulated $\mathrm{CF}$ must provide $20-22 \%$ of crude protein (CP), $2.5-4 \%$ of crude fat, $10-12 \%$ of crude fibre and $68-74 \%$ of total digestible nutrients (TDN), all by per cent mass. One kilogram of any of these mixtures would be required per $2.5 \mathrm{~kg}$ of milk in cows or $2 \mathrm{~kg}$ of milk in buffaloes ${ }^{13}$.

\section{Preparation of mixture}

Once the ingredients (individual feed materials) required for feed formulation are selected, the next step is to choose/calculate the proportions of usage of individual

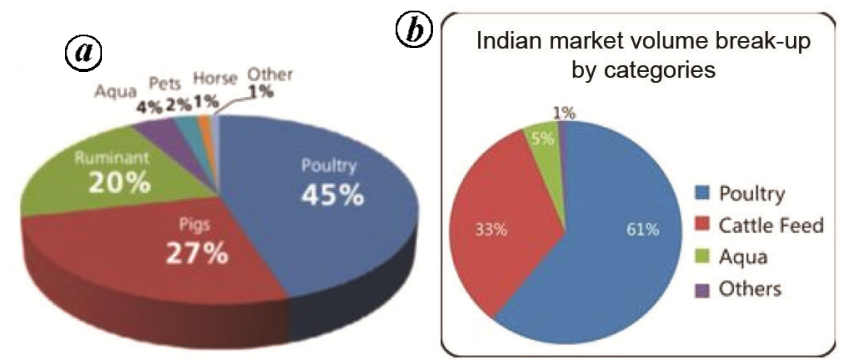

Figure 1. a, Global livestock feed production distribution (source: Anon. ${ }^{23}$ ). $\boldsymbol{b}$, Indian livestock feed production distribution (source: Anon. ${ }^{7}$. ingredients. The proportions of input feed mixture can be selected either by manual calculations (to achieve nutritional value of formulated feed mixture as desired) or using feed formulation software. One such software is MakeFeed Dairy, which contains all the main ingredients mentioned earlier in the text. The properties of each ingredient, viz. dry matter $(\mathrm{g} / \mathrm{kg})$, total digestible nutrients $(\mathrm{g} / \mathrm{kg})$, metabolic energy (Mcal/kg), digestible energy (Mcal $/ \mathrm{kg})$, crude protein $(\mathrm{g} / \mathrm{kg})$, crude fibre $(\mathrm{g} / \mathrm{kg})$, calcium $(\mathrm{g} / \mathrm{kg})$, phosphorus $(\mathrm{g} / \mathrm{kg})$ and cost $(\mathrm{Rs} / \mathrm{kg})$ are preloaded in the software. The maximum inclusion level $(\mathrm{kg} / 100 \mathrm{~kg})$ of individual ingredients is also given in the software. There is provision in the software to edit, add or delete the above-mentioned properties of individual ingredients.

After the individual ingredients are selected to their pre-determined proportions, the next step in feed production is mixing. This usually takes place using a mechanical mixer. The mixer may be a screw auger and trough-type, egg beater-type, etc.

\section{Compound feed production}

$\mathrm{CF}$ is produced in the form of blocks or pellets. Feed blocks are also known as multinutrient blocks ${ }^{12}$. In India, feed block technology was first introduced by the National Dairy Development Board, Anand. In case of feed block production, a mixture of ingredients, preferably tree leaves and cereal crop straws (chopped to small pieces) along with crushed grains, oil cakes, binders (like molasses) and other feed ingredients, viz. minerals and vitamins are selected to predetermined proportions, mixed thoroughly and fed to the feed block forming machine. In case of feed pellet production, only grains (crushed), oil cakes and other feed ingredients, viz. minerals and vitamins are selected to the predetermined proportions, mixed thoroughly and fed to the feed pelleting machine. Mixing can be done either manually or using a mechanical feed mixer. Once mixed, the whole mixture is maintained as such for some time on the smooth surface of a cemented floor so that each particle of feed ingredients absorbs moisture and gets homogenized ${ }^{14}$. Later this mixture is fed to the feed block forming machine or feed pelleting machine through a hopper.

\section{Types of compound feed-producing machines}

\section{Feed block-making machines}

The feed block former may be manually driven screw press-type or power-operated screw press-type and piston/plunger press-type.

Expected benefits from the adoption of feed block technology may be summarized as follows ${ }^{12}$ :

- Simple and efficient technique for long-term conservation of high-moisture agro-industrial by-products

CURRENT SCIENCE, VOL. 118, NO. 4, 25 FEBRUARY 2020 

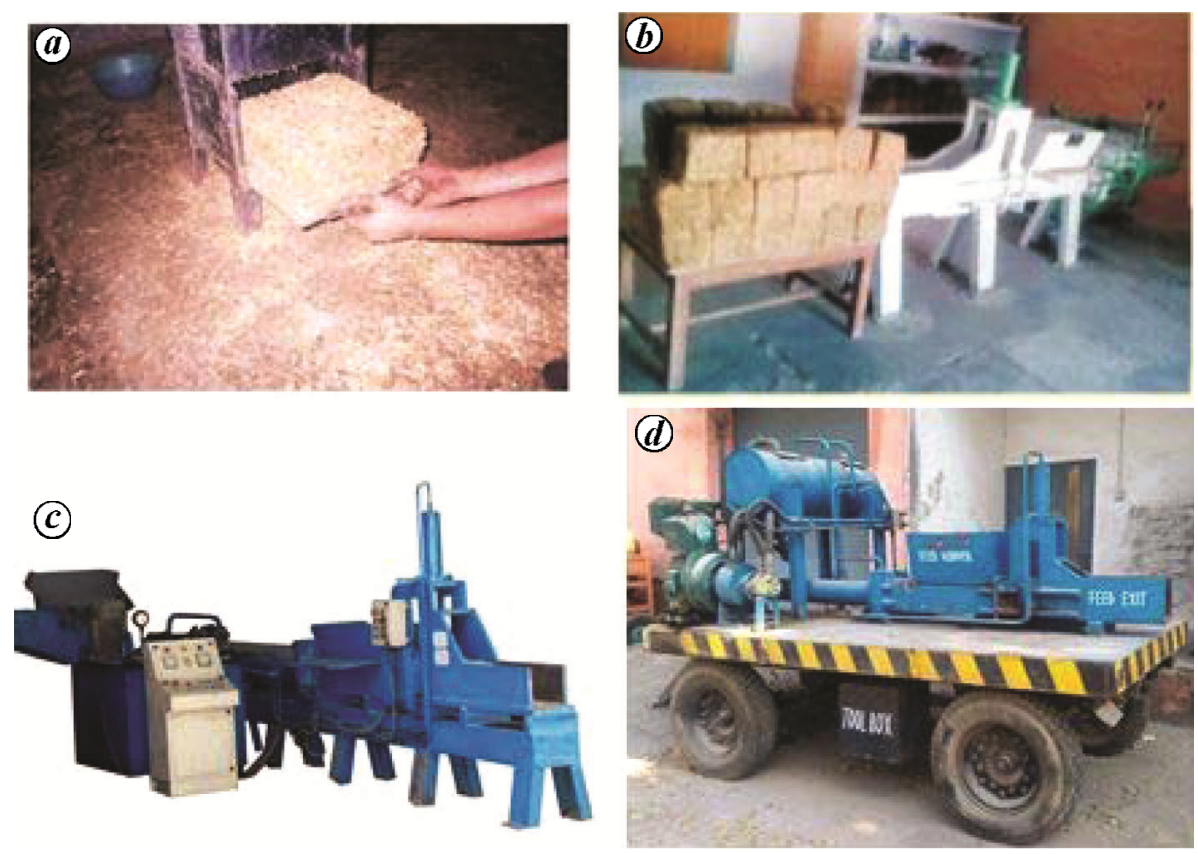

Figure 2. $\boldsymbol{a}$, Manually operated feed block-making machine (source: Khan et al. ${ }^{14}$ ). $\boldsymbol{b}$, Power-operated feed block-making machine (Source: Bohra et al. ${ }^{24}$ ). $c$, Electrically powered hydraulic plunger/piston press-type feed block-making machine (source: Bohra et $a .^{24}$ ). $\boldsymbol{d}$, IC engine-operated, tractor trolleymounted hydraulic plunger/piston press-type feed block-making machine.

(e.g. olive cake, tomato pulp, citrus pulp, date pulp, etc.).

- Ease of transport and of feeding stall-fed and free grazing animals.

- Reduced use of conventional concentrate feeds, thereby feeding cost would be reduced.

- Allows synchronous and fractionated supply of essential nutrients for ruminants fed on low-quality roughages.

- May be used as a carrier of several chemicals and anthelmintic medicines.

- Environment pollution may be reduced.

The manually driven screw press-type machine consists of the upper and lower pressure chambers, pressure plate, and a screw with a handle which is fitted to the pressure plate so as to provide the desired pressure for the preparation of feed blocks as the handle is rotated manually ${ }^{14}$. The feed mixture is transferred to the upper chamber and the block-making machine is operated by rotating the handle, which in turn presses the pressure plate against the bulk feed mixture; as a result the compressed feed blocks will be formed. For removing the prepared feed blocks, pressure is slightly released and packed blocks are taken out of the lower pressure chamber at the bottom of the machine. Figure 2 shows the manually operated feed block-making machine.

Power-operated feed block-making machines are either screw press-type or piston/plunger press-type. The screw press-type machines are electrically driven and have lower capacity. However, the hydraulic piston/plungerpress-machines are either IC engine or electrically driven-type.

Power-operated feed block-making machine can compress all kinds of feed material to rectangular/square shape and of desired thickness and weight (Figure 2). The working pressure of the machine can be up to 6000 PSI (413.68 bar); its output capacity will be $30-40$ blocks/h depending on the size of the machine. The bulk density of the roughage-based feed blocks produced by this machine may be $4-5$ times more than the original feed. It will increase further if fixed with binders and concentrates ${ }^{15}$. The machine is powered using $15 \mathrm{hp}$ electric motor and has the following components: frame, power pack, hydraulic cylinder and electrical control panel.

\section{Feed pelleting machines}

The term 'pellet' is described in the American Society of Agricultural Engineers (ASAE) Standard S269 as an agglomeration of ground ingredients (individual or mixed) commonly used in animal feeds ${ }^{16}$, formed by extruding ingredients by compacting and forcing through die openings by any mechanical process called extrusion ${ }^{8,17}$. Pellets generally have diameters not more than $19 \mathrm{~mm}$ and lengths less than $25 \mathrm{~mm}$ (refs 16, 18). Animals are found to make better gains on pelleted feed than a meal ration. Tests have shown that most animals, if given the choice between the same feed in pellet or mashed form, will prefer the latter ${ }^{10}$. 
Pellet is the most preferred form of CF with advantages like balanced diet, convenience of use and better yield ${ }^{8}$. John and $\mathrm{Manoj}^{9}$ reported the positive opinion of users on $\mathrm{CF}$, and $84 \%$ preferred the pellet form. Some advantages of using pelleted feed are as follows ${ }^{8,10,19-21}$

(a) Pelleting prevents the segregation of ingredients in mixing, handling or feeding process, thereby preventing waste.

(b) With a pelleted feed, each animal receives a wellbalanced diet. Therefore, pelleted feed improves animal performance and feed conversion compared with feeding a meal form of diet.

(c) Feed pellets are much more precise and easier to control over the desired feed ration for individual animals or groups of animals with greater nutritional needs, such as immature stocks or lactating females.

(d) Bulk density is increased, which enhances storage capabilities of most bulk materials. Shipping facilities may also increase, thereby reducing transportation costs. The better flow and handling characteristic of pellets is one of the least mentioned advantages but probably the most important, particularly as it relates to dairy farmers.

The feed pellet production technology for livestock feeding has industrial applications in all regions of the country ${ }^{11}$. In India, several private as well as government (state-owned) industries are involved in the production of $\mathrm{CF}$ pellets. Figure 3 shows the industrial CF pellet production process.

The industrial feed pellet production involves several unit operations. This includes selection and procurement of raw materials, storage of raw materials in the silos, milling or grinding of raw materials, preparation of mixture for the required nutritive value, mixing of different feed ingredients and moistening.

The moistened and thoroughly mixed feed is steadily conveyed to the pelletizer, which is generally a ring die or flat die and roller type. Once the pellets are discharged, they will be shifted to the cooling unit by the conveyor. After the produced feed pellets are cooled down to normal temperature, they are cleaned to remove the fines and dust present. Cooled and cleaned feed pellets are then bagged, labelled and dispatched to the end-users or stored in the storage structures. Figure 4 shows the industrial $\mathrm{CF}$ pellets production process and cattle feed pellets.

Any disruption in trade due to volatility in cost of industrially produced feed pellets could be expensive and unaffordable for the small and marginal dairy farmers ${ }^{4}$. The survey conducted by John and Manoj ${ }^{9}$ reflected that both price and quality of the feed available in the market affect buyer decision by $38.88 \%$. They also mentioned that price, convenience, availability and quality are the major factors influencing the purchase decision of farmers.
Therefore, there is a need to widen the indigenous feed resource base and rely more on locally available resources and their efficient use to produce feed at a lower cost with quality pellet feeds preferred by the users ${ }^{4,8}$. The use of domestically pelleted feed is safer, because there will be zero adulteration in feed ingredients. Although the major essential raw materials required for formulation of complete feeds from the locally available feed resources are within easy reach of the farmers and at low cost, the crucial limiting factor to take full advantage is the lack of appropriate equipment to process the identified raw materials into the required feeds ${ }^{19}$. To meet the demand, especially of dairy farmers at both commercial and subsistence level, research and development on leastcost feed formulation and production of animal feed is an important technical strategy of the livestock feed industry to produce price-competitive products using domestically

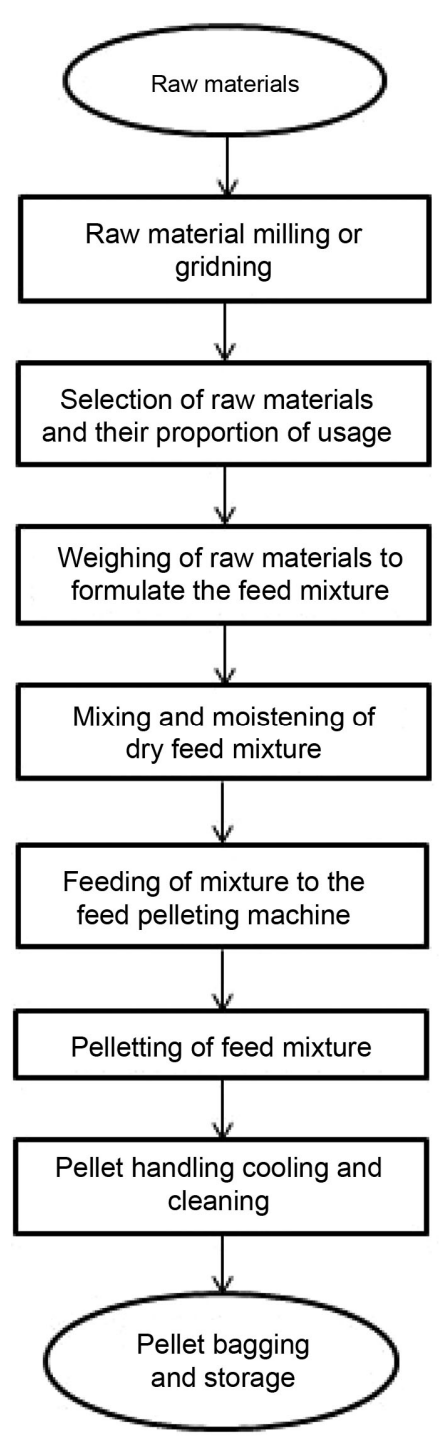

Figure 3. Schematic flow chart of industrial compound feed (CF) pellet production.

CURRENT SCIENCE, VOL. 118, NO. 4, 25 FEBRUARY 2020 

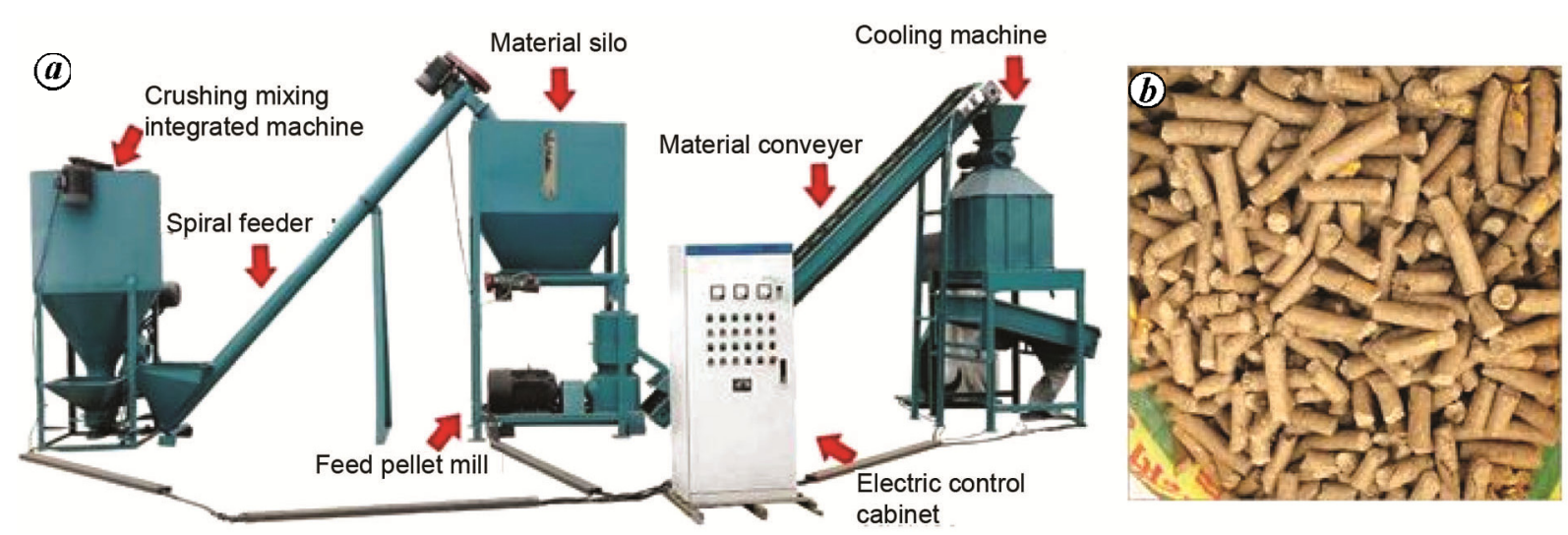

Figure 4. $\boldsymbol{a}$, Pictorial view of industrial CF pellet production (source:Anon. ${ }^{25}$ ). $\boldsymbol{b}$, The 8 mm diameter cattle feed pellets
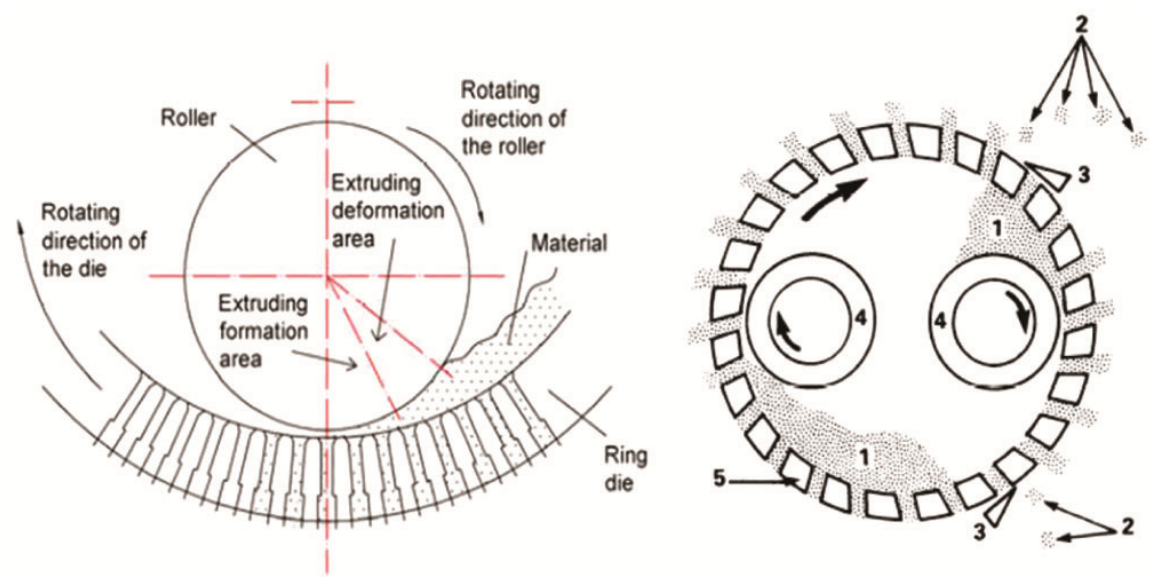

Figure 5. Typical die and roller assembly for producing pellets in a revolving circular die and rollertype pelletizer (source: Gao et al. ${ }^{26} ; 1$, Meal or mash; 2, Pellets; 3, Blades; 4, Rollers and 5, die).

developed pelleting machines. These domestically developed machines must be economically affordable and can be an alternative to the commercially available machines which are quite expensive to be purchased by individuals ${ }^{11}$.

The pelleting machines are broadly categorized as screw extruder-type and roller die-type. The roller die-type pelleting machines are further classified as ring die rollertype and flat die roller-type (either die or roller have driven). The pelleting machines are also classified as manually powered, IC engine or electrically powered and dual-powered (both manual and electrical).

The major components of the pelletizers are pelleting chamber (consists of die plate, die shaft and rollers for roller die-type pelletizers and screw auger, screw auger shaft and barrel which house screw auger for screw extruder-type pelletizers), hopper, pellet outlet, drive mechanism, speed reduction unit, power source, necessary controls, bearings, main frame, etc.

The roller die-type is the most commonly recommended pelleting machine for animal feed production over screw auger-type pelleting machine. In the former pelleting machine, rotating die with roller is the general design for making animal feed pellets, and rotating roller with stationary die is generally used for making wood fuel pellets. Since, feed pellets production is a lowpressure extrusion process, the power requirement per unit output production is comparatively less for rotating die and roller-type pelleting machine. Figure 5 shows typical die and roller assembly to produce pellets in circular die-type pelleting machines.

Figure 6 shows some of the small-scale feed pelleting machines designed and developed by researchers all over the world for production of animal feed pellets at the farm level. Mixing of different ingredients can be done manually if the mechanical mixer is not used for feed pellet production using small-scale feed pelleting machines.

\section{Conclusion}

The possibility and inherent potential in the production of feed blocks and pellets for animal feed have not been 


\section{REVIEW ARTICLES}
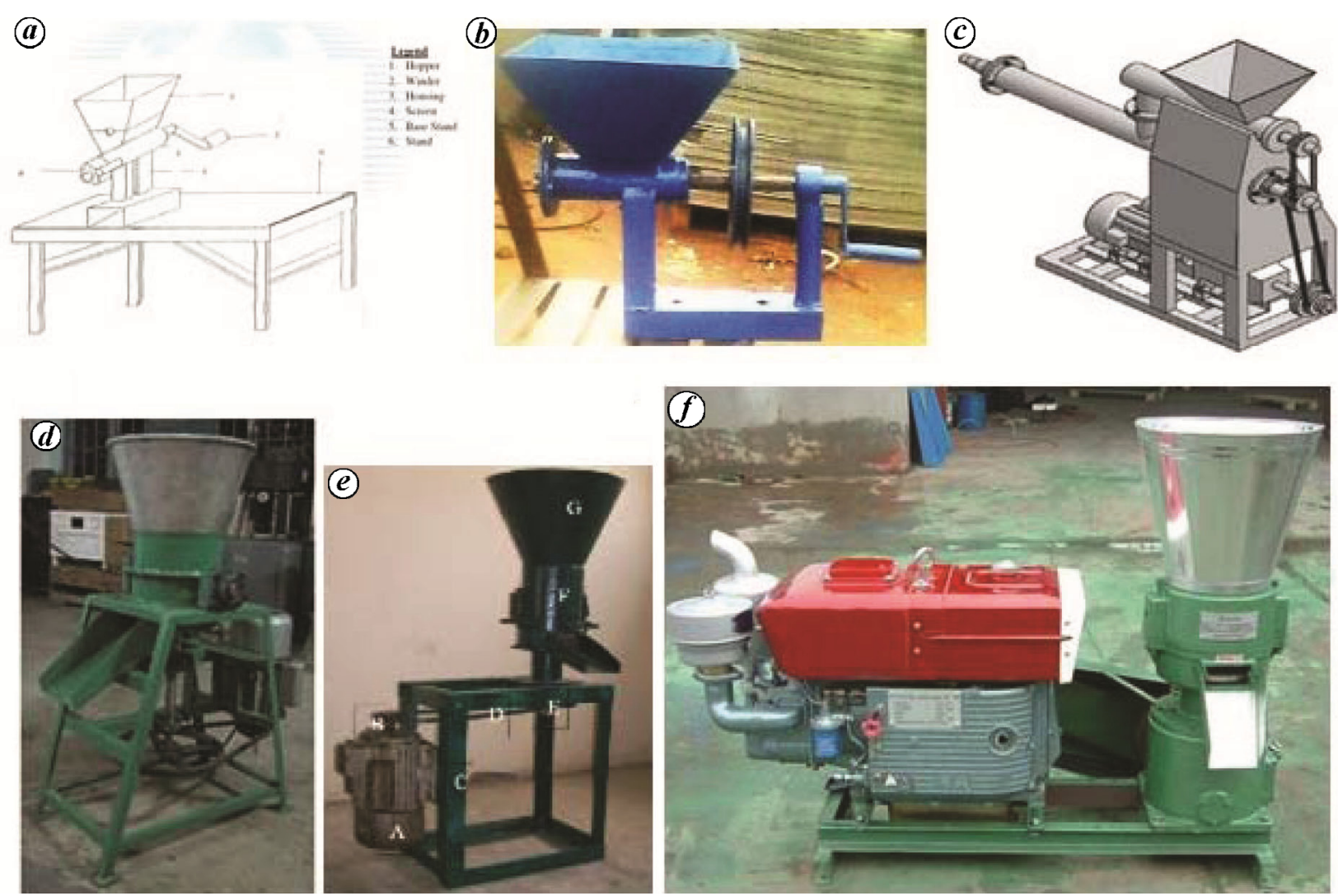

Figure 6. $\boldsymbol{a}$, Manually operated screw extruder-type fish feed pelleting machine (source: Burmamu et al. ${ }^{27}$ ). $\boldsymbol{b}$, Dual-mode laboratorysized screw extruder-type pelleting machine (source: Nwaokocha and Akinyemi ${ }^{17}$ ). $\boldsymbol{c}$, Poultry feed mixing and screw extruder-type pelleting machine (source: $\mathrm{Chikwado}^{28}$ ). $\boldsymbol{d}$ and $\boldsymbol{e}$, Completely electric motor-driven revolving die and roller pellet mill (source: Romallosa and Cabarles $^{19}$, and Kaankuka and Osu ${ }^{29}$ respectively). $\boldsymbol{f}$, IC engine-powered revolving die and roller-type pelletizer (source: Anon. ${ }^{25}$ ).

fully realized, and one of the major challenges is the lowcost machine/equipment necessary for local manufacturer of the same. If small- to medium-sized livestock farmers have access to a feed block-making machine and pellet mill technology that is low cost yet dependable, then it reduces dependency on the high cost of commercial feeds available in the market and makes livestock farming more profitable by taking advantage of availability of different feedstuff at a cheap price at various times of the year, especially during harvest when the high-quality ingredients are available at a low price ${ }^{22}$. Feed blocks should involve cheap ingredients and simple manufacturing equipment. Depending upon the rate of production, different types of mixers and pressing tools could be used. If few blocks are requested, hand mixing may be emphasized and concrete mixer should be used in the case of a large number of blocks. Domestically pelleted feed pellets are safer, because there will be zero adulteration in feed ingredients. However the major limiting factor to take full advantage of domestically produced feed is the lack of appropriate equipment to process the identified raw materials into the required feeds. If the domestically developed feed pelleting machines are available at an affordable cost, they can be an alternative to the commercially available machines which are quite expensive to be purchased by individuals.
Thus it will be possible to produce CF pellets at low cost with quality feeds.

1. Anon., Establishment of cattle feed manufacturing and processing unit, agro and food processing, Project profile presented in Vibrant Gujarat 2017 by the Directorate of animal husbandry, Agriculture and Co-operation Department, Government of Gujarat, 2017.

2. Ahuja, V., Asian livestock: challenges, opportunities and the response. In Proceedings of an International Policy Forum, Bangkok, Thailand, 16 and 17 August 2012, pp. 78-85.

3. Manoj, P. K., Cattle feed industry in India: a macro perspective. Int. J. Business, Manage. Soc. Sci., 2015, 4, 96-101.

4. Makkar, H. P. S., Feed and fodder challenges for Asia and the pacific. Asian livestock: challenges, opportunities and the response. In Proceedings of an International Policy Forum, Bangkok, Thailand, 16-17 August 2010, pp. 82-97.

5. FAO, Successes and failures with animal nutrition practices and technologies in developing countries. In Proceedings of the FAO Electronic Conference, Rome, Italy, 10-15 September 2011, pp. $1-30$.

6. FAO, Balanced feeding for improving livestock productivity increase in milk production and nutrient use efficiency and decrease in methane emission. In Proceedings of the FAO Animal Production and Health, Rome, Italy, 1-5 October 2012, pp. 31-38.

7. Anon., The prospects and challenges ahead for Indian animal feed industry at 50 years of its existence; http://benisonmedia.com/ theprospectsandchallengesaheadforindiananimalfeedindustryat50yearsofitsexistence/ (accessed on 31 August 2016). 
8. Okewole, O. T. and Igbeka, J. C., Effect of some operating parameters on the performance of a pelleting press. Agric. Eng. Int CIGR J., 2016, 18, 326-338.

9. John, M. P. and Manoj, P. K., Prospects of cattle feed industry in India and strategies for utilizing the market potential: a study in Kerala with a focus on factors influencing buyer behaviour. Int. J. Business Gen. Manage., 2014, 3, 1-12.

10. Anon., The pelleting process. California Pellet Mill Co; http:// www.cpm.net/ (accessed on 7 September 2016).

11. Ambalkar, P. P., Shakya, B. R., Bargale, P. C. and Tamhankar, M. B., Status of pelleting technology for integrated aquaculture and livestock feed. Agric. Eng. Today, 2015, 39, 41-46.

12. Salem, H. B. and Nefzaoui, A., Feed blocks as alternative supplements for sheep and goats. Small Ruminant Res., 2003, 49, 275288 .

13. Indian Standard (IS 2052:2009). Compound feeds for cattle (FAD 5: Livestock Feeds, Equipment and Systems) - specification (4th revision). Amendment No. 1, November 2010, pp. 2-3.

14. Khan, M., Pathak, A. K. and Singh, S., Formulation and preparation of densified complete feed blocks with and without condensed tannins: impact on performance of Haemonchus contortus infected goats. J. Anim. Res., 2017, 7, 431-439.

15. Sharma, T., Feed processing as complete feed block for sustainable animal production in arid and semi-arid regions. In Short course on 'feeding of livestock during drought and scarcity', Division of Animal Sciences and Forage Production, Central Arid Zone Research Institute, Jodhpur, ICAR, 2006, pp. 46-53.

16. Kepner, R. A., Bainer, R. and Barger, E. L., Principle of Farm Machinery, CBS Publishers and Distributors Pvt Ltd, New Delhi, 2005, 3rd edn, p. 361.

17. Nwaokocha, C. N. and Akinyemi, O. O., Development of a dual mode laboratory sized pelletizing machine. Leonardo J. Sci., 2008, 1, 22-29.

18. Kaliyan, N. and Morey, R. V., Densification characteristics of corn stover and switchgrass. Trans. ASABE, 2009, 52, 907920 .

19. Romallosa, A. R. D. and Cabarles, J. C., Design and evaluation of a pellet mill for animal feed production. Multidiscip. Res. J., 2011, 6, $1-17$.
20. Zainuddin, M. F., Rosnaha, S., Mohd Noriznana, M. and Dahlan, I., Effect of moisture content on physical properties of animal feed pellets from pineapple plant waste. Agric. Agric. Sci. Proc., 2014, 2, 224-230.

21. Odesola, I. F., Kazeem, R. A. and Ehumadu, N. C., Design and construction of a fish feed extruder. Int. J. Sci. Eng. Res., 2016, 7, 1378-1386.

22. Gabriel, U. U., Akinrotimi, O. A., Bekibele, D. O., Onunkwo, D. N. and Anyanwu. P. E., Locally produced fish feed: potentials for aquaculture development in sub-Saharan Africa. Afr. J. Agric. Res., 2007, 2, 287-295.

23. Anon., Alltech global feed survey-2015; www.alltech.com (assessed on 22 September 2016).

24. Bohra, H. C., Patel, A. K., Rohilla, P. P., Mathur, B. K., Patil, N. V. and Misra, A. K., Feed production technologies for sustainable livestock production in arid areas. Central Arid Zone Research Institute, Jodhpur, 2012, pp. 1-38.

25. Anon., Pellet Mill Manual; http://www.gemco-machine.com/ (accessed on 20 July 2016).

26. Gao, W., Liu, Q., Zhao, R. and Gu, S., Optimize design on the key parts of ring die fuel pellet machine. Adv. Mater. Res., 2014, 860863, 2707-2711.

27. Burmamu, B. R., Aliyu, B. and Tya, T. S. K., Development of a manually operated fish feed pelleting machine. Int. J. Res. Eng. Adv. Technol., 2015, 2, 23-32.

28. Chikwado, U. K., Development and performance test of poultry feed mixing and pelleting machine. Int. J. Sci. Res., 2013, 4, 1161-1166.

29. Kaankuka, T. K. and Osu, D. T., Development of a revolving die and roller fish feed pelletizer. Int. J. Eng. Innov. Res., 2013, 2, $105-110$.

Received 8 February 2019; accepted 30 April 2019

doi: $10.18520 / \mathrm{cs} / \mathrm{v} 118 / \mathrm{i} 4 / 553-559$ 